\title{
Aqueles Trens VINDOS DO SUL ${ }^{1}$
}

\author{
MARIAROSARIA FABRIS
}

RESUMO: Como Luchino Visconti em Rocco e seus irmãos (1960), em Assim é que se ria (1998), Gianni Amelio faz explodir na tela os sentimentos de emigrantes do Sul da Itália que levam para as grandes cidades do Norte industrializado sua fala e seus costumes. Num filme marcado pelas elipses narrativas e pela ambiguidade da trama e das personagens, Amelio focaliza os primeiros anos da migração interna, quando os italianos se descobrem diferentes entre si.

PALAVRAS-CHAVE: cinema italiano; Luchino Visconti; Rocco e seus irmãos; Gianni Amelio; Assim é que se ria; migração; preconceito.

ABSTRACT: Sulla scia di Luchino Visconti in Rocco e i suoi fratelli (1960), in Così ridevano (1998), Gianni Amelio mette a nudo i sentimenti che esplodono quando gente di campagna del Meridione muove verso le grandi città industriali, portando con sé lingua e costumi locali. In questo film, caratterizzato da ellissi narrative e dall'ambiguità della trama e dei personaggi, Amelio focalizza i primi anni dell'emigrazione dal Sud verso il Nord Italia, quando meridionali e settentrionali si scoprono estranei fra di loro.

PAROLE CHIAVE: cinema italiano; Luchino Visconti; Rocco e $i$ suoi fratelli; Gianni Amelio; Così ridevano; migrazione; pregiudizio.

1. Versão revista e ampliada de "Pietro, Rocco e seus irmãos: caminhos e descaminhos da migração interna na Itália pré-boom", conferência de abertura do simpósio temático O estatuto do cinema e da televisão na pesquisa histórica: documento, memória, representação e interdisciplinaridade, realizado no âmbito do XXIV Simpósio Nacional de História (ANPUH), na UNISINOS de São Leopoldo (RS), em 16 de julho de 2007. 
ABSTRACT: In The way we laughed (1998), like in Luchino Visconti's Rocco and his brothers (1960), Gianni Amelio shows the feelings that explode when some country people moves from South to North Italy keeping their own language and usages. In that film, marked by narrative ellipses and ambiguities of plot and characters, Amelio talks about the start of the internal immigration, when Southerners and Northerners saw each other as foreigners. KEYWORDS: Italian cinema; Luchino Visconti; Rocco and his brothers; Gianni Amelio; The way we laughed; immigration; prejudice. 
960. A explosão de $A$ doce vida (La dolce vita) nas telas cinematográficas marcava, no plano simbólico, o fim da era do ressurgimento da Itália das ruínas da Segunda Guerra Mundial e a consolidação de um período de estabilidade econômica no país. Terminada de rodar no ano anterior, a obra de Federico Fellini, apesar de não ter um caráter político, estabelecia um paralelo entre a transformação social e a mudança dos costumes. O peixe monstruoso da sequência final do filme representava a materialização de uma sociedade em que a alta burguesia e a aristocracia decadentes estavam sendo substituídas paulatinamente por uma burguesia endinheirada, inculta e vulgar, à qual estava atrelada uma pequena burguesia medíocre. No seio dessa nova sociedade, o intelectual não tinha mais um papel preponderante, tendo sido destronado pelos meios de comunicação de massa que começavam a impor uma padronização da cultura (DEL VECCHIO, 1995, p. 114; BRUNETTA, 1982, p. 453-454; DUGGAN, 2000, p. 264; UGO, 1994, p. 136; VENE, 1990: legenda da 39 ${ }^{\text {a }}$ foto). No entender do cineasta Vittorio De Seta (apud: BRUNETTA, 1982, p. 631):

A vida mudou, a qualidade de vida; é como se tivesse havido palavras de ordem invisíveis e não expressas, mas que agiram como comandos, como ordens, segundo as quais modelos e valores, particularmente os da vida rural, foram superados e jogados fora, entre o fim dos anos cin- 
quenta e o início dos sessenta, dos quais $A$ doce vida foi um divisor de águas... Êxodos do campo para a cidade, industrialização, consumismo, bem-estar... começaram todas aquelas mudanças cujos prejuízos sofremos hoje... E toda essa transformação dos homens aconteceu e foi vivida como um cataclismo natural. No entanto, creio eu, podia se prever isso e fazer com que se desse de outro modo.

E a vida havia mudado, efetivamente. Já a partir de 1948, a produção industrial italiana tinha começado a progredir, graças também à mão-de-obra barata - os salários pagos no país estavam entre os mais baixos da Europa -, uma vez que havia uma oferta abundante de trabalhadores, principalmente dos que provinham das áreas rurais. A competição por um emprego nas fábricas do triângulo industrial (Turim-Milão-Gênova) reduzia o risco de reivindicações salariais que pudessem incidir sobre os custos finais dos produtos, o que facilitou as exportações. Na primeira metade dos anos 1950, a Itália estava praticamente reconstruída ${ }^{2}$ e, de 1955 em diante, a economia do país teve um incremento tal a ponto de, no início dos anos 1960, estar com quase toda a sua força de trabalho empregada e a lira, tendo se tornado uma moeda forte, conquistar o Oscar financeiro. Era o chamado "milagre econômico", favorecido pelos subsídios e pelos empréstimos dos Estados Unidos e por uma conjuntura política estável, o centrismo. ${ }^{3}$ Nesse período, a Itália passou de país agrícola a industrial, ${ }^{4}$ entrando no rol das oito nações mais industrializadas do mundo, o que acelerou a urbanização, reduziu o desemprego, ${ }^{5}$ diminuiu a pressão da questão agrária graças à emigração, em especial no Sul, e incrementou o uso de bens de consumo (eletrodomésticos e veículos motorizados, principalmente). Não resolveu, no entanto, problemas de infraestrutura - escolas, hospitais, transporte público, casas populares -, nem beneficiou as classes menos favorecidas. ${ }^{6}$

Os autores não são unânimes quando se trata de datar esse período de prosperidade econômica, que teria se desenvolvido desde o início, o meio ou o fim dos anos 50 até meados ou quase fins dos 60. Tendo em vista que 1952-1953 foi uma temporada ruim para a economia italiana; que, em 1954, a taxa de desemprego foi elevada e assim se manteve até 1959; que, entre 1957 e 1958, com a retomada da indústria norte-americana, a local ficou em compasso de espera, ao mesmo tempo em que, com a criação da Comunidade Econômica Européia, a 25 de março de 1957, o país se voltava mais e mais para as exportações; que, só depois de 1958 e notadamente entre 1961 e 1964, os salários começaram a se equi-

\footnotetext{
2 A reconstrução do país deu-se entre 1943-44 e 1953, graças a subsídios norte-americanos, principalmente os provenientes do plano Marshall (1947-1952). Em 1949, a Itália esteve entre as nações signatárias do Pacto Atlântico (OTAN).

3 Governo de coalizão que dominou a vida política do país entre 1947 e 1962, integrado pela Democracia Cristã, pelo Partido Liberal Italiano, pelo Partido Republicano Italiano e, a partir de 1952, pelo Partido Social-Democrático Italiano.

4 No imediato pós-guerra, a agricultura representava 48\% da produção do país; em 1951, entre 42,2\% e 47,1\% (dos quais 56,9\% no Sul); em 1963, 25,5\%; no fim dos anos 70, apenas 16\% (EUG, 1997, p. 760; KOGAN, 1977, p. 183).

5 No pós-guerra, a Itália tinha mais de dois milhões de desempregados, dos quais num primeiro momento, a indústria só conseguiu absorver uma pequena parte (GRAZIANI, 1976, p. 312).

6 Além das referências assinaladas nas notas 3 e 4, para os dados contidos neste parágrafo, cf. SMITH, 1972, p. 741; ROMANO, 1978, p. 247; CAROCCI, 1995, p. 79; VILLARI, 1976, p. 109; SCALFARI, 1981; FAZZOLARI, 1981; PECCIANTI, 1988, p. 125-126; EUG, 1997, p. 760; DUGGAN, 2000, p. 264.

7 Início dos anos 50-meados dos 60 (PECCIANTI, 1988, p. 125); meados dos anos 50-1964 (UGO, 1994, p. 138-139); anos 50-1963/64 (AGNESE, 1988); 1955-1963 (CAROCCI, 1995, p. 79); 1958-1962 (CASTRONOVO, 1981); 1958-1963 (DUGGAN, 2000, p. 262; GINSBORG, 1990); 1959-1962 (SCALFARI, 1981, p. 97); 1959-1963 (FAZZOLARI, 1981).
} 
parar aos dos demais países europeus; que, se, em 1962, a Itália conheceu um período de estagnação, a partir de 1963 teve um incremento produtivo, cujos efeitos se prolongaram até o "outono quente" de 1969 (quase o fim daquele ano, portanto), quando o mercado internacional se retraiu (CASTRONOVO, 1976, p. 28, p. 35; SMITH, 1972, p. 741, p. 745, p. 759-760; ROMANO, 1978, p. 245; CAROCCI, 1995, p. 80; GUICHONNET, 1986, p. 125; DI NOLFO, 1986, p. 272), a tendência é concordar com as datas estabelecidas por Norman Kogan (1977, p. 173), que situa o boom econômico entre o segundo semestre de 1959 e fins de 1963. De fato, foi no verão de 1959 que a taxa de desenvolvimento se elevou e assim, depois das férias - logo, de setembro em diante -, nos grandes centros do Norte do país, começou a ser adotada a semana de cinco dias de trabalho; e foi entre 1963 e 1964 que os industriais recorreram à recessão para frear os aumentos salariais que os trabalhadores passaram a reivindicar no verão de 1962 (KOGAN, 1977, p. 173; VENÈ, 1990, p. 288; FOA, 1976, p. 273-274; CASTRONOVO, 1981).

O milagre econômico atingiu principalmente a região Noroeste, onde se concentravam os capitais financeiros, e beneficiou uma pequena parcela da população italiana - quase 25\% (KOGAN, 1977, p. 193-194; GINSBORG, 1990, p. 216-217; GUICHONNET, 1986, p. 125). Mesmo nos chamados "oásis de modernização" (DUGGAN, 2000, p. 262), nem todos usufruíam das benesses apregoadas pelos meios de comunicação de massas; entretanto (VENÈ, 1990, p. 288),

bastava achar-se, à noite ou de madrugada, numa estação de trem do Norte, de tráfego intenso, para se dar conta do incomensurável caminho percorrido. Os homens e as famílias transportados pelos trens do Sul, seja os que haviam concluído sua viagem, seja os que desciam apenas para encher cantis e garrafas nas bicas e tornavam a subir nos vagões que se dirigiam para além das fronteiras, pareciam atrasados de quinze anos em relação ao presente. [...] Ninguém conseguiu calcular, na época, quão numeroso fosse esse exército que vinha do passado. Soube-se depois que, no fim dos anos 50, as migrações internas para as cidades do Norte e os êxodos para a Alemanha e a Suíça não haviam alcançado ainda seu ápice.

A sequência inicial de Rocco e seus irmãos (Rocco e i suoi fratelli, 1960) exemplifica bem essa descrição. Noite alta, na estação central de Milão: através de grades, ${ }^{8}$ vê-se a chegada de um trem. Uma mulher madura, toda trajada de preto e envolta em seu xale,

8 Segundo Gian Piero Brunetta (1982, p. 753), essas grades marcariam a separação entre a cidade (que está atrás da câmera) e os recémchegados, focalizados ainda num espaço indefinido. Para Gianni Amelio (CROWDUS, 2002, p. 15), nessa, como nas demais realizações de Visconti, há sempre um filtro entre o diretor e a realidade. Nisso, o diretor milanês estaria muito próximo de Giovanni Verga, o qual, em sua recusa do populismo, filtrava através da norma culta (a língua italiana), o linguajar popular (a fala regional) de suas personagens (FABRIS, 2001, p. 18). 
desce com quatro dos seus filhos de um daqueles velhos vagões, que, na época da reconstrução, foram destinados às linhas ferroviárias do Sul do país. Os rapazes estão vestidos de forma simples, um deles tendo como abrigo uma espécie de manto, ainda usado nas áreas rurais, e carregam trouxas e cestas. Estão alcançando Vincenzo, o irmão mais velho, que já está estabelecido na capital da Lombardia, onde, no fim dos anos 1940, a renda era quarenta e oito vezes superior à de Matera (CAROCCI, 1995, p. 77), uma das cidades da Basilicata, região da qual provinha a família Parondi.

O filme de Luchino Visconti levava para as telas o novo fenômeno social com o qual a Itália se defrontava: o de um deslocamento demográfico dentro de seu território, contínuo, desordenado e feito às custas de enormes sacrifícios. Embora as motivações não fossem muito diferentes das que, no passado, tinham levado um enorme contingente humano a cruzar os mares para "fazer a América", a partir do pós-guerra, ao lado da Argentina e dos Estados Unidos, haviam surgido novas destinações: Venezuela, Austrália e Canadá, no além-mar; dentre os países europeus, França, Suíça, Bélgica e Alemanha Ocidental, nos quais os estrangeiros exerciam as atividades mais precárias e menos remuneradas; e as grandes cidades do Noroeste da península itálica, para as quais afluíram pessoas provenientes, em sua maioria, das zonas rurais: do Sul (Campânia, Basilicata, Apúlia, Calábria, Sicília e Sardenha) e, em menor medida, das regiões centrais (notadamente das Marcas) e do Vêneto (no Nordeste), onde o subemprego atingia índices alarmantes de $48 \%, 43,8 \%$ e $41,3 \%$, respectivamente. ${ }^{9}$

Em 1950, pela primeira vez, era realizada uma reforma agrária na Itália, incentivada pelos democrata-cristãos, para fazer frente aos movimentos reivindicatórios, apoiados pelos comunistas, que haviam agitado o campo em 1944 e em 1948. Este último havia sido lembrado “indiretamente” em O moinho do Pó (Il mulino del Po, 1949), no qual, ao retratar fatos ocorridos no século anterior, quando os trabalhadores rurais, em contato com o nascente socialismo, organizaram as primeiras greves, Alberto Lattuada levava para as telas a "consciência da exploração" (BRUNETTA, 1982, p. 302, p. 287), assim como havia feito Visconti, em A terra treme (La terra trema, 1948), em relação aos pescadores. Pela reforma agrária, entre 700.000 e 800.000 hectares de terra foram distribuídos para mais de 100.000 famílias do Sul e da Maremma (região litorânea bonificada entre a Toscana e o Lácio). As propriedades, no entanto, eram pequenas, pouco férteis, faltavam meios para o cultivo, o que fazia com que as condições de vida no campo continuassem inaceitáveis. Ademais, principalmente no Sul, a resistência às cooperativas levou muitas vezes ao fracasso da iniciativa, quando não ao endividamento dos trabalhadores rurais (CAROCCI, 1995, p. 78; UGO, 1994, p. 138).

Em outra sequência de Rocco e seus irmãos, Visconti faz o protagonista lembrar o que significou essa experiência para as pessoas de sua região de origem:

9. Entre 1958 e 1963, mais de meio milhão de italianos (dos quais 73,5\% do Sul) migrou para o Norte da Europa; a Alemanha Ocidental e a Suíça absorveram 86\% dessa mão-de-obra, em 1963 (GINSBORG, 1990, p. 211, p. 220; GRAZIANI, 1976, p. 319; CAROCCI, 1995, p. 74, p. 80; DI NOLFO, 1986, p. 276). 
Eu tinha um amigo na aldeia, aliás, mais de um, garotos da minha idade, mas tão pobres, que você nem pode imaginar. Então, um dia, lhes deram a ilusão de terem um pedacinho de terra para cultivar, mas uma terra que arrebentava os braços para tirar algo dela, e você levava quase meio dia para alcançá-la. Assim, um belo dia, esses coitados se rebelaram, mas os algemaram e os prenderam em Matera, em Potenza.

O malogro da reforma agrária, ao lado da arrancada da industrialização - a exigir e a atrair, cada vez mais, novos braços para as grandes cidades -, levou a uma rápida mudança na estrutura social do país. Assim, camponeses se transformaram em operários nas fábricas do Norte, uma vez que os industriais não se mostraram muito propensos a abrir fábricas no Sul e a contribuir para o desenvolvimento daquelas regiões (nas quais praticamente só o Estado investiu), visto que lhes convinha mantê-las como um repositório de mão-de-obra barata. A FIAT, por exemplo, afirmava que, no Sul, faltavam matéria-prima e fontes energéticas para implantar uma indústria automobilística, bem como um mercado e trabalhadores especializados (SMITH, 1972, p. 747; GRAZIANI, 1976, p. 318-319; DI NOLFO, 1986, p. 272). Já em 1953, no filme Napoletani a Milano, Eduardo De Filippo ironizava essa suposta incapacidade para as atividades industriais dos sulistas, os quais, uma vez alcançado o Norte, revelavam sua eficiência (CIRIO, 2007).

De novo, não há unanimidade dos autores, desta vez ao se tentar estabelecer o tamanho desse deslocamento demográfico em massa, que levou 17 milhões de italianos a deixarem sua localidade de origem e cujo ápice se deu entre 1955 e 1963: grosso modo, pode-se dizer que, nos anos 1950-1960, mais de 9 milhões de pessoas se deslocaram dentro do próprio país e que, de 1951 a 1961, deixaram sua terra de 1.250 .000 a mais de 2 milhões de habitantes do Sul, número que chegou a 2.500 .000 na década seguinte. Com isso, Milão, que recebeu $70 \%$ de migrantes do Vêneto e da própria Lombardia e $30 \%$ do Sul (entre 1958 e 1963, sobretudo), teve um crescimento populacional de $24 \%$, enquanto o de Turim foi de 43\%, ao acolher principalmente trabalhadores da Apúlia (jurisdição de Foggia e de Bari) e da Calábria (jurisdição de Reggio Calabria). Nesse período, Turim recebia cerca de 80.000 sulistas a cada ano, fato que a transformou na terceira maior cidade do Sul da Itália, depois de Nápoles e de Palermo (CERVELLATI, 1976, p. 344; CAROCCI, 1995, p. 80; GINSBORG, 1990, p. 219-220; DUGGAN, 2000, p. 264; VILLARI, 1976, p.: 110; GRAZIANI, 1976, p. 321; PECCIANTI, 1988, p. 126). O coro de dialetos meridionais que Gianni Amelio consegue orquestrar na sequência que abre Assimé que se ria (Così ridevano, 1998) - com a chegada do trem vindo do Sul, na estação de Porta Nuova em Turim -, é magistral para exemplificar esta última afirmação.

Calcula-se que a nova onda migratória tenha atingido cerca de $30 \%$ da população 
italiana (53 milhões, na época, dos quais 20 milhões no Sul), tendo constituído, junto com a escolarização de massa e a difusão das transmissões televisivas, iniciadas a 3 de janeiro de 1954, um fator de modernização e unificação do país. Graças à televisão, novos hábitos e novos comportamentos iam sendo assimilados, e aquele idioma que só alguns conheciam começou a afirmar-se enquanto língua comunicativa unitária, ao lado das tradicionais falas regionais, de modo que, como salienta Gian Franco Venè (1990, p. 262): "Pela primeira vez, os vocábulos italianos correspondiam ao que os olhos viam”.

Assim, aos poucos, o italiano passou a ser empregado regularmente por $25 \%$ dos nativos e compreendido por mais de $70 \%$ da população, mas, até alcançar esses índices, em meados dos anos $1970,{ }^{10}$ o contraste entre as falas regionais do Norte e do Sul impediu muitas vezes o mais simples ato comunicativo. Numa das primeiras sequências de Rocco e seus irmãos, a comunicação entre a matriarca do clã Parondi e o cobrador do bonde só é possível pela repetição de palavras isoladas, gestos, fotografias (BRUNETTA, 1982, p. 592), como se se tratasse de uma conversa entre um nativo e um estrangeiro, o que vem atestar que eram culturas diferentes, mentalidades diferentes que estavam em jogo (DUGGAN, 2000, p. 264-265):

Homens e mulheres, frequentemente iletrados, cujas famílias antes raramente tinham deixado a própria comunidade rural ao longo dos séculos, e que só falavam dialetos, de repente se acharam no meio das luzes de néon, dos bens e do trânsito de uma imensa cidade apressada.

Como dirá Luigi Tenco, em 1967, na canção “Ciao, amore, ciao”, de um dia para o outro, essas pessoas davam um salto descomunal não só no espaço, mas no tempo, se viam jogadas num universo totalmente desconhecido e isso as desnorteava, as desarraigava, as humilhava:

E poi mille strade / grige come il fumo, / in un mondo di luci / sentirsi nessuno. / Saltare cent'anni / in un giorno solo: / dai carri nei campi / agli aerei nel cielo, / e non capirci niente e aver voglia di tornare da te. / [...] / Non saper fare niente / in un mondo che sa tutto, / e non avere un soldo / nemmeno per tornare. ${ }^{11}$

Para poder usufruir das migalhas do bem-estar que o milagre econômico parecia oferecer a todos, a população rural pagou um preço muito elevado. A labuta nas grandes cidades custava "dor" e "sacrifício", como afirma uma das personagens de Assimé que seria, mas era a única saída para sobreviver. Se o desemprego diminuía e os salários aumentavam, em

10. Dados de 1975 (DE MAURO, 1981; CAROCCI, 1995, p. 80-81).

11. "E depois mil ruas / cinzentas feito fumaça, / num mundo de luzes / sentir-se um zé-ninguém. / Dar um salto de cem anos / num único dia: / dos carros de boi no campo / aos aviões no céu, / e não entender nada e desejar voltar para você / [...] / Não saber fazer nada / num mundo que sabe tudo / e nem ao menos ter um tostão / para poder voltar". Aqui, assim como no caso de trechos de filmes e dos textos cuja versão para o português não foi assinalada nas referências bibliográficas, trata-se de tradução nossa. 
contrapartida, as aldeias do Sul se despovoavam e nelas sobravam apenas velhos, mulheres e crianças (SMITH, 1972, p. 747-748), à espera de alcançarem seus familiares no Norte.

A jornada de trabalho nunca era inferior a dez ou doze horas, quando não atingia as cento e vinte horas semanais. Como lembra Gian Franco Venè (1990, p. 288), os sulistas eram "pedreiros de dia, artesãos à noitinha, vigias à noite, guardadores de carro aos sábados, ajudantes de pizzaria aos domingos”, para poderem ser alcançados pelas famílias e subtrair-se à solidão. Trabalhavam em empregos temporários (de três a seis meses) em pequenas fábricas ou na construção civil, onde quase nunca se obedecia às normas de segurança. Além disso, as condições de moradia eram assustadoras, pois esses trabalhadores viviam nos locais mais degradados do centro, em pensões miseráveis (quatro ou cinco pessoas em cada cômodo) ou eram confinados na extrema periferia, nas chamadas cidades-dormitório, denominadas coree ${ }^{12}$ na área metropolitana de Milão, onde os casebres surgiam clandestinamente à noite para evitar que a polícia expulsasse os moradores do terreno invadido (DUGGAN, 2000, p. 264; UGO, 1994, p. 137; GINSBORG, 1990, p. 225). Ao acompanhar a trajetória de Giovanni Scordìa na cidade de Turim, particularmente no fim dos anos 1950, Gianni Amelio reconstitui com maestria todos estes aspectos. Vários momentos de Assim é que se ria, parecem ecoar a seguinte descrição que Venè (1990, p. 272-273) faz dos pedreiros, uma das tantas profissões de Giovanni:

Os pedreiros, aliás, eram a tropa do exército mais maltrapilho jamais surgido nas cidades do Norte. Vestiam, no trabalho, camisetas ou malhas esfarrapadas, calças puídas, amarradas na cintura com um barbante, das quais os joelhos despontavam entre os rasgões, sapatos deformados sem cadarços, endurecidos pela cal, gibões sobre a pele nua, estranhos chapéus de folhas de jornal. [...] Trabalhavam com o tempo bom ou ruim: debaixo da chuva, pulavam de um andaime para outro, com um saco de cimento cobrindo a cabeça, ou com um pedaço de plástico amarrado no pescoço, com as pernas nuas, parecendo, nesse caso, aves agourentas da tempestade. Falavam, aliás, gritavam em todos os dialetos meridionais: compreendiam a língua, mas não conseguiam se fazer entender.

Já em O teto (Il tetto, 1956), no entanto, Vittorio De Sica e seu roteirista, Cesare Zavattini, haviam abordado essa temática, focalizando a luta de um jovem casal para erguer, num terreno baldio da periferia de Roma, as paredes de uma minúscula casa dentro da qual construir uma nova vida. De fato, Roma também, enquanto capital administrativa do país, foi atingida pela onda migratória, com suas áreas periféricas que inchavam e onde as condições de sobrevivência contrastavam violentamente com as benesses usufruídas 
pelos protagonistas da doce vida felliniana, como bem demonstrou Pier Paolo Pasolini em Desajuste social (Accattone, 1961) (FABRIS, 2007; FABRIS, 1993).

O quadro das manifestações culturais que permitiriam abordar a migração interna é vasto, mas, para aprofundar a reflexão sobre esse fenômeno, é melhor determo-nos sobre dois exemplos dentre os mais significativos, os já citados Rocco e seus irmãos e Assim é que se ria. Por sua temática, principalmente pelos laços de amor e de morte que o permeiam, a realização de Amelio poderia ser considerada uma espécie de refilmagem da obra de Visconti, ${ }^{13}$ mas não é bem assim, pois, se este transformou o drama da migração numa tragédia familiar, aquele, em vez de inserir seus personagens num universo mítico (AMELIO apud CROWDUS, 2002, p. 15) ou arquetípico (BRUNETTA, 1982, p. 754), focalizou esse mesmo tema de forma mais controversa, dando-lhe um alcance mais coletivo e uma conclusão mais cruel, ao eliminar a dicotomia entre o bem (Rocco) e o mal (Simone).

Embora o período focalizado pelos dois filmes seja praticamente o mesmo - o do cineasta lombardo se passa na segunda metade dos anos 1950; ${ }^{14}$ o do diretor calabrês, de 1958 a 1964 -, no primeiro, a passagem do tempo é mais fluida (as referências temporais mais concretas são o episódio de Rocco durante o serviço militar e o momento em que Ciro diz que era um pouco maior do que Luca quando chegou em Milão), enquanto, no segundo, a sucessão cronológica dos fatos dá o ritmo da trama.

As duas histórias começam com a chegada dos chamados treni del sole ("trens do sol") ou treni della speranza ("trens da esperança"), ${ }^{15}$ respectivamente em Milão e em Turim, lembrando, como já vimos, o maior fenômeno social da Itália naquele período: o daquela "revolução invisível", como a denomina Gianni Amelio (apud CROWDUS, 2002, p. 15), que foi a migração do campo (principalmente do Sul do país) para as grandes cidades industriais do Noroeste. Enquanto Visconti registra o fenômeno em seu nascedouro, Amelio - um terrone ("matuto"), um napoli ("paraíba" ou "baiano") 16 como seus personagens - mergulha naquela realidade, mas com certo distanciamento, graças à passagem do tempo, optando por um tom menor para contar o drama dos dois irmãos; na obra de Visconti, ao contrário, o acento melodramático predomina e vai crescendo.

Os dois filmes são constituídos por grandes blocos narrativos. No do cineasta milanês, temos uma introdução e cinco macro-sequências, ou, como prefere dizer Gian Piero Brunetta (1982, p. 753-755), um prólogo e cinco atos, ao classificar o filme como uma tragédia, a da desagregação de uma família de camponeses, que, em contato com a realidade urbana, perde seu caráter de núcleo unitário, pagando um alto preço pelas transformações acarretadas na vida de cada um de seus membros. A referência teatral não é descabida ao se lembrar que na base de Rocco e seus irmãos está também a primeira versão de

14. Segundo Amelio (apu: CROWDUS, 2002, p. 15), embora em seu filme pareça estar contando a mesma história de Visconti, ele se sente mais próximo de Roberto Rossellini ou mesmo de Vittorio De Sica. 14. A chegada da família Parondi em Milão data de outubro de 1955, segundo o roteiro de filmagem (VISCONTI. 1967, p. 111).

15. Treni del sole eram os comboios que vinham do Sul da Itália, chamado também Mezzogiorno ("meio-dia”) por ser mais ensolarado do que o Norte do país. Treno della speranza é o termo empregado por Venè (1990: legenda da 32ª foto). O início da década de 1950 representou um período de esperança para os sonhos e as ambições das camadas menos favorecidas e da pequena burguesia italiana (DI NOLFO, 1986, p. 276). A esses trens foram dedicadas duas músicas na segunda metade da década de 1960: "Il treno che viene dal sud", composta e cantada por Sergio Endrigo, em resposta a "La donna del sud”, de Bruno Lauzi, da qual o próprio Endrigo havia sido intérprete. A uma visão idílica sobre a migração interna, que Lauzi tematizava por meio de uma trama amorosa, Endrigo opunha uma descrição realista, eivada de amargura e desesperança.

16. Terrone (derivado de terra) é a alcunha que os habitantes do Norte da Itália dão aos do Sul, porque esta região é mais ligada às atividades agrícolas. Napoli, como Giovanni é chamado no filme, era o termo empregado depreciativamente para designar um sulista imigrado para o Norte. Seu emprego, provavelmente, se deve ao fato de todas as regiões do Sul, exceto a Sardenha, pertencerem ao Reino de Nápoles ou Reino das Duas Sicílias, antes da unificação do país (1860). 
O panorama visto da ponte, de Arthur Miller, peça que o diretor havia montado em 1958: o tema da (i)migração, o drama do ciúme, a fatalidade dos vários destinos que se cruzam caracterizam as duas obras.

Cada ato ou macrossequência leva o nome de um dos irmãos - Vincenzo, Simone, Rocco, Ciro e Luca, o que faz com que cada personagem tenha sua vida contada mais de perto -, mas o discurso não é truncado, porque as várias histórias se entrelaçam. Como dizia o próprio autor (VISCONTI, s.d.), Rocco e seus irmãos é a "história de Rosaria, uma mulher da Lucânia, enérgica, forte, teimosa, mãe de cinco filhos, 'fortes, bonitos, saudáveis’, que são para ela como os cinco dedos da mão”, afirmação que traduz bem a idéia dessa diversidade e de união entre os irmãos, ao mesmo tempo em que revela a filiação à obra de Giovanni Verga desse filme também, uma vez que a expressão "que são para ela como os cinco dedos da mão", ecoa o início de I Malavoglia, quando o escritor siciliano assim apresentava a família de padron 'Ntoni: "E a família de patrão 'Ntoni era realmente disposta como os dedos da mão" (VERGA, 2002, p. 14). Num texto sintomaticamente intitulado "Rocco, un seguito di La terra trema", Visconti (s.d.) explicita essa filiação: ${ }^{17}$

Para Rocco, uma história na qual eu já pensava há muito tempo, a influência maior que tive foi, talvez, de Giovanni Verga: Os Malavoglia, de fato, obcecou-me desde a primeira leitura.

E, pensando bem, o núcleo principal de Rocco é o mesmo do romance de Verga: lá, 'Ntoni e sua família, na luta pela sobrevivência, para livrar-se das necessidades materiais, tentavam a empreitada da "partida de tremoços"; aqui os filhos de Rosaria tentam o pugilismo: e o boxe é a "partida de tremoços" de Os Malavoglia. Assim o filme se aparenta com A terra treme - que é a minha interpretação de Os Malavoglia -, do qual constituiu quase o segundo episódio.

O início da sequência da neve, com a câmera a revelar a moradia miserável em que Rosaria e seus filhos estão acomodados, lembra bastante a apresentação da casa dos Vallastri no filme de 1948, com as fotos das duas famílias retratadas ainda em sua integridade. ${ }^{18}$

17. Não podemos esquecer que o roteiro de filmagem previa um prólogo na Lucânia - com o enterro do chefe da família Parondi no mar, o leilão dos trabalhadores na aldeia, Rosaria a lamentar a desgraça que se havia abatido sobre sua família e a decisão de vender as parcas terras para migrar - em que se explicitava tanto a filiação verguiana do filme, quanto a linha de continuidade que Visconti estabelecia entre A terra treme e Rocco e seus irmãos (VISCONTI et al., 1967, p. 105-111).

18. Para o argumento e o roteiro de Rocco e seus irmãos, Visconti e seus colaboradores basearam-se em alguns dos contos que Giovanni Testori reuniu no livro Il ponte della Ghisolfa (1958), como, por exemplo, em “Cosa fai Sinatra?”, do qual extraíram o episódio do estupro de Nadia. Há, ainda, uma série de ecos de outros textos, na representação do ambiente esportivo, na relação de Simone com uma mulher mais velha (a dona da lavanderia), inspirada em vários trechos de Testori, nos quais a dona de um bar se envolve com um de seus garçons; na luta de Rocco, quando lhe machucam um dos supercílios, em que o cineasta recria com eficácia o clima de "Il ras (parte prima)"; na tensão homossexual presente em vários momentos do filme e no livro, como por exemplo, no conto "Il Brianza". Mais do que uma citação direta, no entanto, tratou-se de reinterpretações, do aproveitamento de nuanças, detalhes e atmosferas desta e de outras obras: da derivação dostoievskiana de Rocco (que lembra Myskin de O idiota), Rosaria e Nadia, ao próprio título do filme, o qual remete ao do romance José e seus irmãos, de Thomas Mann, e à Bíblia; da presença de Verga e Miller à de Georges Bizet, cuja ópera Carmen inspirou o assassinato da prostituta por parte de Simone (FABRIS, 2005; BENCIVENNI, 1995, p. 284). Para a sequência da morte de Nadia, além da derivação operística, poderíamos assinalar também uma origem literária, se atentarmos para o fato de que um dos roteiristas do filme foi Vasco Pratolini. Em Un eroe del nostro tempo (1949), o protagonista matava a amante, numa passagem muito parecida à que será filmada por Visconti. Referindo-se a esse momento-chave do romance do escritor florentino, assim o descrevia Ruggero Jacobbi (1972, p. 21): "Sobra a vítima designada, Virginia, e se torna, de fato, o cordeiro sacrifical; acaba sendo crucificada no mesmo lugar (o parque, a neve) onde aconteceram todas as cenas decisivas para Sandrino [...]. O último passeio de Sandrino e Virginia é a viagem infernal de duas pessoas que se arrastam e arrastam sua memória até um ponto insustentável. Aqui, cada um obedecerá à própria natureza: ele, a violência; ela, o martírio". 
O filme de Gianni Amelio divide-se em seis capítulos, como ele mesmo os chama (apud CROWDUS, 2002, p. 16), estrutura que lhe permite proceder por elipses, embora cada capítulo implique o outro. Ao focalizar aqueles anos cruciais da recente história italiana, anos de grandes transformações principalmente para as populações do campo recém-chegadas às cidades, a cada capítulo, apesar de seguir um fio temporal bem marcado pelas datas, a trama reserva aos espectadores sempre alguma novidade, algum aspecto psicológico inesperado:

$\begin{array}{lll} & \text { 20 de janeiro de 1958 } & \text { Chegadas } \\ 7 \text { de fevereiro de } 1959 & \text { Enganos } \\ & \text { 10 de outubro de 1960 } & \text { Dinheiro } \\ 7 \text { de abril de } 1961 & \text { Cartas } \\ \text { Domingo } & 5 \text { de junho de } 1962 & \text { Sangue } \\ & \text { de julho de } 1964 & \text { Famílias }\end{array}$

Assim é que se ria narra a história de dois irmãos sicilianos que imigraram para o Piemonte. Pietro, o mais jovem dos Scordia, ${ }^{19}$ havia sido enviado para Turim ainda adolescente, a fim de tornar-se professor de primeiro grau, e lá vivia na casa de parentes. Giovanni, ao contrário, era analfabeto; estava visitando o irmão, alguns anos depois, e, diante das condições em que este vivia, resolve ficar e fará todos os sacrifícios possíveis para que Pietro possa continuar a estudar e viver em lugares mais decentes. O irmão, porém, não aceita facilmente o destino que outros traçaram para ele e preferiria ser um trabalhador braçal como Giovanni, o qual, envolvido em atividades cada vez menos lícitas, dá início à sua escalada social. A relação entre os dois é ambígua, entremeada de amor e de rancor, ambiguidade que culminará no sacrifício que Giovanni exige do caçula: assumir a culpa de um crime que ele cometeu. Aqui também, como na obra de Visconti, o núcleo familiar, pelo qual tanto se luta, pois representa o ponto de referência dessas personagens, se despedaça diante da realidade dos fatos.

No filme de Amelio, assim como em Rocco e seus irmãos, é necessário um sacrifício feito de sangue para que indivíduos arrancados de seu ambiente de origem consigam redefinir-se num contexto novo e desconhecido para (re)construir a própria identidade: é o que acontece na interessantíssima sequência que leva à imolação de Pietro, que, trocando de papel com seu irmão, o qual renunciou a muitas coisas por ele, cumprirá a pena no lugar de Giovanni; é o que acontece na belíssima e terrível sequência da morte de Nadia, esfaqueada por Simone, cego de ciúmes porque a prostituta preferiu Rocco a ele.

Essas duas sequências, se, de um lado, vêm atestar a fúria com que essas pessoas,

19. O sobrenome Scordìa, como bem lembra Gary Crowdus (2002, p. 15), pode ser associado ao verbo scordare ("esquecer"). É interessante associar esta observação ao fato de, nas aldeias calabresas, a América do Sul - portanto o destino de muitos imigrantes - ser chamada a terra d'u scuordo, ou seja, a terra do esquecimento (GINSBORG, 1990, p. 211). 
incapazes de romperem um círculo vicioso, respondiam à violência recebida, incrementando, dessa forma, as estetísticas da criminalidade (SMITH, 1972, p. 748); de outro, remetem a mentalidades de outros lugares - questões de honra ou de dinheiro resolvidas por um lei pessoal, portanto, fenômenos de deterioração de uma vida social, trazidos das aldeias do Sul (GALASSO, 1981, p. 103) - e até mesmo a práticas ancestrais. Estas últimas, por exemplo, estão presentes na rememoração de Rocco, seguida pelo movimento da câmera, que, ao acompanhar o olhar de Ciro, para sobre a expressão trágica de Simone numa das fotos afixadas na parede da sala: "Você lembra, Vincé, que o mestre-de-obras, quando começa a construir uma casa, atira uma pedra na sombra da primeira pessoa que está passando. [...] Porque é necessário um sacrifício para que a casa se erga sólida”.

Nos dois filmes, o tema central é o da integração (alcançada ou não); no de Visconti, em suas várias facetas; no de Amelio, de forma aparentemente mais simples. Em Rocco e seus irmãos, a estrutura diegética, que obedece à idade decrescente dos filhos de Rosaria, permite um movimento pendular constante entre integração e não integração (quando não desintegração). Em suma, poderíamos dizer que Vincenzo representa a integração alcançada; Simone, a recusada (embora almejada); Rocco, a possível (da qual não faz questão); Ciro, a buscada; Luca, a que está em suspenso (porque poderá acontecer ou não) (CANOVA, 2000). De fato, por ocasião de seu noivado, Vincenzo declara não ter vontade alguma de regressar à aldeia e de querer constituir sua família em Milão; Ciro, por sua vez, está esquecendo a língua materna e se integrando cada vez mais à grande cidade, como observa o irmão mais velho; Simone, que em sua primeira luta representa a Lombardia, sendo chamado traidor por seus conterrâneos, acaba se tornando um pária na nova sociedade; para Luca, tanto Rocco (em seu discurso depois da vitória), como Ciro (na sequência final do filme), desejam que ele consiga regressar. E Rocco - em sua conversa com Nadia, em Livorno, quando a moça lhe pergunta se não gosta de Milão - deixa transparecer toda sua inadaptação a uma realidade que não é a dele e na qual os bens de consumo supérfluos se tornaram prioritários:

Gosto, mas é lá na aldeia que deveríamos ter meios para viver melhor, onde nascemos, onde fomos criados. Acredito que não consiga me achar numa cidade grande, porque não nasci nem me criei nela. Falo por mim, mas estou pensando também em meus parentes, irmãos, conterrâneos. Muitos conseguem acostumar-se, ambientar-se logo, até ter os mesmos desejos que os outros têm. Eu não, e acho também que isso não seja certo. Gostaria de desejar um carro, por exemplo, mas só depois de ter desejado e obtido o que vem em primeiro lugar, quer dizer, um emprego seguro, fixo, uma casa e a certeza de ter o que comer todos os dias. 
Em Assim é que se ria, a integração que parecia realizável por meio de Pietro acontecerá através de Giovanni, que entendeu qual é o jogo da nova sociedade. Visconti havia deixado em aberto a possibilidade de um futuro regresso à aldeia natal, na figura do pequeno Luca, o qual, talvez não por acaso, carregue no próprio nome um pedaço da denominação da região de origem: Luca < Lucânia (o diretor emprega ainda o antigo nome da região e não o novo, Basilicata). Amelio, ao contrário, faz com que Pietro empreenda sua viagem de regresso, mas em condições adversas, quase como um desarraigado, porque fechado num instituto para menores infratores.

Para evidenciar essa diferença bastaria lembrar que o cineasta milanês abre e fecha o filme com uma canção pungente que fala da saudade da aldeia natal - "Minha bela aldeia onde eu nasci, meu coração contigo deixei aí” (“Bello paise mio addò so' nato, lo cuore mio con te l'aggio lasciato") - que ouvimos, pela última vez, enquanto o menino, num movimento contrário ao de três operários, se afasta por uma rua, deixando para trás a fábrica na qual trabalha seu irmão Ciro. O diretor calabrês abre e fecha o filme com os contrastes linguísticos e culturais entre os que se sentem superiores e os que são considerados inferiores na escala sociogeográfica italiana.

Se, no início de Assim é que se ria, o jovem Scordìa se sente superior à família de apulianos, embora os ajude em sua chegada na nova cidade - em relação ao pai analfabeto, capaz de expressar-se só em linguagem regional, e em relação ao filhinho que não sabe como quatro elefantes conseguem caber num carro popular -, no fim, ele também escolherá o silêncio, a não comunicação, quando, no trem que o leva de volta para a Sicília depois da breve pausa do batizado do sobrinho, seu acompanhante, um educador do Norte da Itália, torna a propor-lhe, naquela língua que Pietro não adquiriu de todo, a mesma pergunta sobre os elefantes.

O rapaz escolheu o silêncio porque dentro dele tinha-se apagado até a voz atávica ainda audível na obra de Visconti -, representada no filme de Amelio pelo murmulho do mar que Pietro não mais ouve. Um mar presente em Assim é que se ria metaforicamente, num de seus momentos mais significativos. Durante uma aula de francês, está sendo feito um ditado a partir da canção La mer, de Charles Trenet. Enquanto os outros alunos escrevem, Pietro se deixa embalar pela melodia, pela letra, pela inflexão da voz do cantor e começa a desenhar, com traços praticamente infantis, algumas ondas e um barquinho com uma minúscula vela. É um momento de integração de uma cultura pessoal, a da infância, deixada para trás mas ainda presente dentro dele, e uma cultura geral, européia, a da adolescência, assimilada, é verdade, mas devolvida fora dos parâmetros estabelecidos pela escola, microcosmos daquela sociedade.

É um momento quase tavianiano do filme. Em Pai patrão (Padre padrone, 19761977), quando o jovem Gavino Ledda começa a “alfabetizar-se”, arrancando os primeiros 
acordes de sua sanfona - aos quais respondem o som de uma flauta e o do choro de outros dois pastorzinhos -, Paolo e Vittorio Taviani sobrepõem legendas a essas imagens, para explicar a nós, espectadores, que detemos outra língua, os sinais daquele código que não possuímos (FABRIS, 1993-1994). Assim como não possuímos o de Pietro.

Em Assim é que se ria, também, a expressão linguística é recusada (o jovem desenha) e o francês resulta mais familiar do que a língua italiana, ${ }^{20}$ porque capaz de despertar as lembranças, nas quais a natureza (la mer, o mar), e logo a aldeia, se opõe à urbe. O que nos faz entender que, no fundo, Pietro é um "desajustado" ao qual nunca ninguém perguntou se estava apto àquele tipo de "progresso". Foi-lhe imposto um modelo de língua, de educação, de vida, porque era o modelo vencedor. E, quando o rapaz canta La mer para o irmão, talvez seja esta a mensagem que quer transmitir-lhe, e não a de que finalmente era alguém por ter conseguido se diplomar, por ser capaz de expressar-se numa língua estrangeira. Mas, talvez, a expressão de nossos sentimentos mais profundos é sempre uma língua estrangeira para os ouvidos dos outros, se não conseguirmos sintonizar a frequência de onda exata.

É interessante notar que praticamente no mesmo período em que o filme de Amelio era lançado, em Prefiro o barulho do mar (Preferisco il rumore del mare, 1999), Mimmo Calopresti apresentava a história de um rapaz calabrês, o qual, tendo-se transferido para Turim numa comunidade religiosa para "desajustados", fugindo assim à internação num instituto para menores infratores, se acha numa cidade sombria, hostil para com os italianos do Sul, e, no fim, prefere voltar à sua aldeia, irreconciliado com um modo de vida que não era o seu. A mesma irreconciliação do protagonista de Trevico-Turim: viagem no Fiat-Nã (Trevico-Torino: viaggio nel Fiat-Nam, 1972), no qual Ettore Scola, embora discuta a questão da migração na década seguinte à focalizada por Amelio, mostra como continuavam persistindo os mesmos problemas. Em vários momentos do filme, assim como em Rocco e seus irmãos, é lembrado que as pessoas não deveriam ser obrigadas a deixar o rincão de origem, porque deveria haver trabalho para todos, em qualquer lugar. Ao tomar consciência da alienação imposta pelos ritmos da produção industrial, Fortunato Santo Spirito afirma que a diferença entre o campo e a fábrica, embora nos dois casos o trabalho seja extenuante, é que lá, pelo menos, cada um sabe para o que serve a própria labuta.

Em Rocco e seus irmãos, apesar do forte impacto da modernidade, há, ao mesmo tempo, a fascinação por aquele "mundo de luzes" "“un mondo di luci”, cantado por Luigi Tenco, alguns anos mais tarde, em Ciao amore ciao) e isso é evidente nas exclamações de Simone, no bonde que, da estação, leva a família Parondi para a periferia milanesa: “Olhe, Rocco! Olhe as vitrines! Quanta luz! Parece de dia!”. No fim, bem ou mal, haverá a aceitação da inserção, embora paire sobre ela o fantasma da saudade.

É verdade que Visconti se predispõe a olhar para a sua Milão com os olhos de um imigrado, motivo pelo qual os espaços urbanos parecem (e são) imensos, frios, geométri- 
cos; em todo caso, não deixa de haver uma atitude de disponibilidade humana por parte das pessoas locais, apesar do preconceito que assoma em vários momentos. A Turim de Amelio é escura, chuvosa, envolta em neblina, fechada em seus preconceitos contra os imigrados explorados até não poderem mais, obrigados a dormir em tugúrios ou como ratos a viver de rejeitos (de trabalhos que outros não querem mais fazer) e a tornar-se invisíveis se não souberem comportar-se como os turineses.

É esse o jogo que Giovanni aprende, a agir sempre sorrateiramente (onde vive, onde trabalha), até ser considerado um “cristão" igual aos outros pelo pai da esposa turinesa que arranjou para si. E Giovanni entendeu tão bem o jogo a ponto de transformar-se por sua vez num explorador do trabalho dos conterrâneos, num usurário, num senhorio de acomodações precárias, onde uma mesma cama é ocupada por várias pessoas, em turnos, num empregador de trabalhadores clandestinos; em suma, em alguém que enriqueceu fazendo os outros cuspirem sangue, o mesmo sangue que ele cuspiu para que o irmão se tornasse um professor primário, sempre com um sorriso nos lábios, sempre em nome de uma bondade, de uma generosidade que os outros retribuíram a peso de ouro, como Pietro, que se entregará à polícia no lugar do irmão, quando este esfaqueia um homem.

É o caminho que leva ao capitalismo selvagem o escolhido por Giovanni, que não percebe que existe outra saída além daquela de perpetuar o esquema da exploração. Numa das sequências mais admiráveis do filme, depois de ter saído da cadeia, para a qual fora levado pelos distúrbios causados na escola de Pietro (onde fora procurá-lo), Giovanni se encontra sozinho numa espécie de quadrilátero de ruas, circundado por trabalhadores que protestam, carregando bandeiras vermelhas, os quais parecem barrar-lhe o caminho. "Fala" com os livros do irmão que está carregando, como se estivesse escrevendo uma carta a Pietro, perguntando-lhe onde errou, enquanto o eco de Bandiera rossa continua a espalhar-se pelo ar. ${ }^{21}$ É um dos momentos mais íntimos, mais pessoais de Assim é que se ria, em que Giovanni, fechado em sua “obsessão” de vencer, vê diante de si um único caminho a ser percorrido. Mas não é o de Pietro, assim como não tinha sido o caminho da família Parondi. O discurso que Ciro faz a Luca, no fim de Rocco e seus irmãos, traduz a ideologia de Visconti: ${ }^{22}$

Também na nossa aldeia a vida irá mudar para todos, porque também no Sul os homens estão aprendendo que o mundo tem de mudar. Alguns dizem que o mundo desse jeito não será melhor, mas eu, Luca, acredito nisso. E sei que, amanhã, sua vida será mais justa e mais honesta.

Se o porta-voz ideológico de Visconti acaba sendo Ciro, que almeja um futuro melhor, o de Amelio é Pietro, para quem não há mais esperanças, não há mais ilusões, não

21. Na opinião de Gianni Amelio (apud CROWDUS, 2002, p. 15), Giovanni está inserido numa sociedade em cujas leis não acredita, por isso a família, que é um refúgio, passa a ter um valor obsessivo, pois ditado pelos laços de sangue. Afora isso, só há desconfiança e incapacidade de abrir-se para os outros, esquecendo sentimentos básicos de amizade, de solidariedade. É interessante prestar atenção na data desta sequência, 7 de abril de 1961, pois foi entre 1959 e 1961 que os trabalhadors do triângulo industrial se organizaram na defesa de seus diretos (GRAZIANI, 1976, p. 322), algo com que Giovanni não concordava.

22. Segundo Glauber Rocha (1983), toda a fala final de Ciro reflete, na realidade, a lucidez do diretor que descrê do ser humano, ao vislumbrar nesse operário um burguês em potencial , uma vez que ele representa "a verdade na monstruosa sociedade capitalista", uma verdade que, para se impor, tem de destruir tanto o mal (Simone), quanto quem é capaz de compreendê-lo e justificá-lo (Rocco). Já para Gianni Amelio (apud CROWDUS, 2002, p. 15), na visão de Visconti, dentro da lógica da nova sociedade industrializada, não haveria lugar nem para o mal nem para o bem, pois ambos fazem parte de uma cultura que tem que ser deixada para trás para se ingressar no mundo civilizado. Idéia semelhante havia sido expressada por Claude Prévost (1967, p. 82), para quem Ciro seria "um homem do presente”, a quem Visconti teria confiado o papel de explicar, “didaticamente, as razões essenciais do drama”. 
há uma identidade nacional a ser alcançada se as diferenças entre Norte e Sul não forem aceitas. Por isso, pensando na mensagem que Gianni Amelio quis transmitir, vem à lembrança um filme de Pietro Germi, no qual um grupo de sicilianos atravessa a Itália, seguindo uma trilha "de incompreensões, de incomunicabilidade", na qual cada etapa da viagem se revela "devastada e dilacerada pelos conflitos sociais" (BRUNETTA, 1982, p. 421). Assim mesmo, não esmorecem diante da perspectiva de alcançar a França e naquele país tentar uma nova vida. Chamava-se O caminho da esperança (Il cammino della speran$z a, 1950)$ e foi um dos pioneiros na focalização desse tema.

Em Assimé que se ria, ao contrário, tudo parece perdido. No trem, que, do Piemonte, leva de volta para a Sicília um professor do Sul e um educador do Norte, ainda há lugar para a incomunicabilidade, para a incompreensão (seja em 1964, seja em 1998), porque parece nos dizer Amelio - só quando esta for superada, talvez possamos tornar a escutar o murmulho do mar.

É uma observação que valia para 1964, último período focalizado pelo filme, quando os nortistas não perceberam que era necessário um tempo maior para que essas pessoas, vindas de aldeias nas quais, muitas vezes, ainda persistiam esquemas medievais, pudessem passar de uma sociedade arcaica para uma sociedade moderna, estabelecendo não um corte radical, mas uma linha de continuidade. É uma observação que valia para 1998, ano de realização da obra de Amelio, e que parece valer também para os dias de hoje, ${ }^{23}$ consequência de uma série de questões anteriores à unificação do país, que ficaram pendentes mesmo com o novo Estado ${ }^{24}$ e precisam ser resolvidas para que, finalmente, a unidade da Itália se afirme na diversidade de culturas de seus filhos.

22. Em artigo, escrito para a revista Nouvel Observateur, Umberto Eco (2007), ao comentar o livro Dictionnaire amoureux de Naples, de Jean-Noël Schifano (um apaixonado pela cidade de Nápoles, à qual dedicou vários textos), faz a seguinte afirmação: "Mas sou um italiano do Piemonte (região que, há séculos, é culturalmente mais francesa que italiana), e entre um piemontês e um napolitano existe bem mais diferença que entre um sueco e um brasileiro da Bahia. Por essa razão, me ver diante de um francês (mesmo que seja um francês de pai italiano) mais napolitano que qualquer outra pessoa é algo que me provoca um sentimento de mal-estar".

23. Ennio Lorenzini, em Quanto è bello lu murire acciso (1976), ao focalizar a revolução falhada de Carlo Pisacane, apresentou uma amarga reflexão sobre a continuidade das instituições no Sul da Itália, quando da passagem do reino dos Bourbon para o reino da Casa de Savóia (FABRIS, 1983). 


\section{Referências bibliográficas}

AGNESE, M. L. L'età del benessere. In: AGNESE, M. L. (Org.). Storia dei giovani prima, durante e dopo il Sessantotto. Milano: Mondadori, 1988. p. 36-37.

AMELIO, G. Birth and death of a nation. Cineaste, New York, v. XXVIII, no 1, p. 19-20, winter 2002.

BENCIVENNI, A. Rocco e i suoi fratelli. In: DI GIAMMATTEO, F. (Org.). Dizionario del cinema italiano. Roma: Editori Riuniti, 1995. p. 283-284.

BRUNETTA, G. P. Storia del cinema italiano dal 1945 agli anni ottanta. Roma: Editori Riuniti, 1982.

CANOVA, G. Rocco e i suoi fratelli: Visconti e le aporie anestetiche della modernità. In: PRAVADELLI, V. (Org.). Il cinema di Luchino Visconti. Roma: Bianco \& Nero, 2000. p. 175-186.

CAROCCI, G. Storia dell'Italia moderna dal 1861 ai nostri giorni. Roma: Newton Compton Editori, 1995.

CASTRONOVO, V. Boom economico: sulla pelle del cafone. In: STORIA DI UNA REPUBBLICA: enciclopedia politica dell'Italia dal 1946 al 1980. Roma: Editoriale L’Espresso, 1981. p. 100.

. Economia e classi sociali. In: CASTRONOVO, V. (Org.). L'Italia contemporanea 1945-1975. Torino: Einaudi, 1976. p. 3-60.

CERVELLATI, P. L. Rendita urbana e trasformazione del territorio. In: CASTRONOVO, V. (Org.). L'Italia contemporanea 1945-1975. Torino: Einaudi, 1976. p. 337-377.

CIRIO, R. Napoletani a Milano. L’Espresso, Roma, ano LIII, nº 12, p. 31, 29 mar. 2007.

CROWDUS, G. The lack of historical memory: an interview with Gianni Amelio. Cineaste, New York, v. XXVIII, $\mathrm{n}^{0}$ 1, p. 14-18, winter 2002.

DE MAURO, T. Dialetti: i giovani parlano in lingua. In: STORIA DI UNA REPUBBLICA: enciclopedia politica dell'Italia dal 1946 al 1980. Roma: Editoriale L’Espresso, 1981. p. 103.

DEL VECCHIO, M. La dolce vita. In: DI GIAMMATTEO, F. (Org). Dizionario del cinema italiano. Roma: Editori Riuniti, 1995. p. 113-114.

DI NOLFO, E. Le paure e le speranze degli italiani (1943-1953). Milano: Mondadori, 1986.

DUGGAN, C. A concise history of Italy. Cambridge: Cambridge University Press, 2000.

ECO, U. A cidade das mil contradições. Tradução Clara Allain. Folha de S. Paulo, supl. Mais!, nº 797, p. 10, 8 jul. 2007.

EUG - Enciclopedia Universale Garzanti. Milano: Garzanti, 1997.

FABRIS, M. O espelho opaco. Insieme, São Paulo, nº 4-5, p. 91-102, 1993-1994.

Figli di una vecchia canzone... La Settimana del Fanfulla, São Paulo, ano XVI, nº 844/166, p. 3, 6 jan. 1983. 
Giovanni Verga: uma lição de história. In: VERGA, G. Cenas de vida siciliana. Tradução Mariarosaria Fabris et al. São Paulo: Berlendis \& Vertecchia, 2001. p. 11-18.

A margem da redenção: considerações sobre Accattone. Revista de Italianística, São Paulo, v. 1, nº 1, p. 91-99, jul. 1993.

Presença da literatura nos filmes de Luchino Visconti: o diálogo com Giovanni Verga. Revista de Italianística, São Paulo, nº X-XI, p. 195-202, 2005.

O teto. In: FRANCO, G. C. (Org.). Olhares neo-realistas. São Paulo-Brasília: Centro Cultural Banco do Brasil, 2007. p.100-101.

FAZZOLARI, T. Automobili: cala un torrente di ferro. In: STORIA DI UNA REPUBBLICA: enciclopedia politica dell’Italia dal 1946 al 1980. Roma: Editoriale L’Espresso, 1981. p. 101.

FOA, V. Sindacati e classe operaia. In: CASTRONOVO, V. (Org.). L'Italia contemporanea 1945-1975. Torino: Einaudi, 1976. 1976, p. 253-276.

GALASSO, G. Migrazioni interne: la penisola s'accorcia. In: STORIA DI UNA REPUBBLICA: enciclopedia politica dell'Italia dal 1946 al 1980. Roma: Editoriale L’Espresso, 1981. p. 102-103.

GINSBORG, P. The "economic miracle", rural exodus and social transformation, 1958-63. In: A history of contemporary Italy: society and politics 1943-1988. London, Penguin Books, 1990, p. 210-253.

GRAZIANI, A. Mercato interno e relazioni internazionali. In: CASTRONOVO, V. (Org.) . L'Italia contemporanea 1945-1975. Torino: Einaudi, 1976. p. 307-336.

GUICHONNET, P. Histoire de l'Italie. Paris: Presses Universitaires de France, 1986.

JACOBBI, R. Vasco Pratolini. In: PRATOLINI, V. Un eroe del nostro tempo. Milano: Mondadori, 1972. p. 5-21.

KOGAN, N. L'Italia del dopoguerra: storia politica dal 1945 al 1966. Roma-Bari: Laterza, 1977.

PECCIANTI, M. C. Storie della storia d'Italia. Casale Monferrato-Firenze: Marietti-Manzuoli, 1988.

PRÉVOST, C. Natureza e cultura em Luchino Visconti. In: VISCONTI, L. Rocco e seus irmãos. Tradução Noênio Spinola. Rio de Janeiro: Civilização Brasileira, 1967. p. 53-91.

ROCHA, G. Visconti e os nervos de Rocco. In:__. O século do cinema. Rio de Janeiro: Alhambra, 1983, p. 165-166.

ROMANO, S. Storia d'Italia dal Risorgimento ai nostri giorni. Milano: Mondadori, 1978.

SCALFARI, E. La lira vince l'Oscar della moneta. In: STORIA DI UNA REPUBBLICA: enciclopedia politica dell’Italia dal 1946 al 1980. Roma: Editoriale L’Espresso, 1981. p. 97-99.

SMITH, D. M. Storia d'Italia dal 1861 al 1969. Bari: Laterza, 1972.

UGO, G. Piccola storia d'Italia. Perugia: Guerra, 1994.

VENÈ, G. F. Vola colomba: vita quotidiana degli italiani negli anni del dopoguerra: 1945-1960. Milano: Mondadori, 1990.

VERGA, G. Os Malavoglia. Tradução Aurora Fornoni Bernardini \& Homero Freitas de Andrade. 
São Paulo: Ateliê Editorial, 2002.

VILLARI, L. Ricostruzione: dieci anni di incertezze. In: STORIA DI UNA REPUBBLICA: enciclopedia politica dell'Italia dal 1946 al 1980. Roma: Editoriale L'Espresso, 1981. p. 13.

VILLARI, R. La crisi del blocco agrario. In: CASTRONOVO (Org.) L'Italia contemporanea 19451975. Torino: Einaudi, 1976. p. 105-143.

VISCONTI, L. Rocco, un seguito di La terra trema. www.cinemaitaliano.net., s.d.

VISCONTI, L. et al. O roteiro de filmagem. In: VISCONTI, L. Rocco e seus irmãos. Tradução Noênio Spinola. Rio de Janeiro: Civilização Brasileira, 1967. p. 105-290 